\title{
Socioeconomic differentials in mortality among men within Great Britain: time trends and contributory causes
}

Perla J Marang-van de Mheen, George Davey Smith, Carole L Hart, Louise J Gunning-Schepers

\begin{abstract}
Study objective-To assess the size of mortality differentials in men by social class in Scotland as compared with England and Wales, and to analyse the time trends in these differentials.

Subjects-Men from England and Wales and Scotland around each census from 1951 to 1981.

Methods-Poisson regression analysis was used to calculate relative indices of inequality for disease specific and all cause mortality as a measure of mortality differentials between social classes. This measure is not dependent on the size of the social class groups, so it can be used to compare the magnitude of differentials over time periods during which the relative sizes of social class groups change.
\end{abstract}

Main results-While overall death rates were higher in Scotland than in England and Wales around the 1951, 1961, and 1971 censuses the relative indices of inequality indicated smaller mortality differences between social classes in Scotland. Inequality, as indexed by the relative index of inequality, increased over time in both Scotland and England and Wales, but to a greater degree in Scotland, resulting in greater social class mortality differentials for Scotland in 1981 (the relative index of inequality increased from 1.40 to 2.43 for England and Wales, and from 1.22 to 2.57 for Scotland between 1951 and 1981). This greater increase in the magnitude of inequalities in all cause mortality in Scotland seemed to result from increasing social class differentials in cardiovascular disease, accidents and external causes, and "all other causes of death". Examining the trends in overall death rates, it seems that the greater increase in social class differences in Scotland occurred because of the greater decrease in death rates among the privileged social groups, in combination with a smaller decrease (or a greater increase) in the death rates in the lower social class groups.

Conclusions-This study has shown that trends in mortality and in inequalities in mortality differ within Great Britain. Although death rates were higher in Scotland than in England and Wales, smaller mortality differentials by social class were found in Scotland over the period 1951 to 1971. By 1981, however, social class mor- tality differentials were greater in Scotland than in England and Wales. The greater increase in the social class differentials over time in Scotland, may have contributed to the worsening overall mortality profile in Scotland as compared with England and Wales that occurred between 1971 and 1981.

\section{(F Epidemiol Community Health 1998;52:214-218)}

Socioeconomic mortality differences in England and Wales have increased over the past 40 years. ${ }^{1-5}$ Recently, increased attention has been given to the international variation in the size of mortality differences associated with socioeconomic position. Kunst and Mackenbach show that countries differ in the size of their socioeconomic mortality differences, with small differences being observed in Norway and Denmark and large differences in France. ${ }^{6}$

Scotland is known to have higher death rates than England and Wales. Carstairs and Morris argued that this higher mortality around the 1981 census is because of the much higher levels of deprivation in Scotland as compared with England and Wales. ${ }^{7}$ In another study it was shown that the mortality differentials between the west of Scotland and the south of England were largely explained by age, height, lung function, socioeconomic status, and smoking. ${ }^{8}$ The relative magnitude of socioeconomic mortality differentials within Scotland and England and Wales has not been examined previously, however.

The purpose of this study is to assess the magnitude of the mortality differences by social class in Scotland as compared with England and Wales over the period 1951 to 1981 , to determine whether the higher overall mortality rate in Scotland is accompanied by greater socioeconomic mortality differentials within Scotland. We investigate which causes of death have contributed to increasing social class mortality differences and whether these were different in Scotland than in England and Wales.

\section{Methods}

All analyses were restricted to men aged 15 to 64 years of age because of difficulties in comparing social class measures in women, based on their own or their spouses occupation, over time. The population of 65 years and older was excluded, because the meaning of social class coded on death certificates for 
people who are no longer working is uncertain. Census data from 1951, 1961, 1971, and 1981 regarding social class of a $10 \%$ representative sample is used to estimate the denominator population and social class classified according to occupation at time of death as the numerator. ${ }^{9-15}$ These numerator data come from the years surrounding the census year, but for reasons of presentation we refer to the central census year throughout the text. The $10 \%$ sample refers to on average 140000 men in Scotland and to about 1.3 million men in England and Wales. More recent data on mortality by social class for Scotland and England and Wales (around the 1991 census) will not be published until late 1997 at the earliest. Data for England and Wales have been published in summary form, ${ }^{16}$ but not the age specific death rates required for these analyses, and for Scotland no data have yet been published.

The different causes of death were grouped as: all infectious diseases, all malignant neoplasms, all cardiovascular diseases, all respiratory diseases, all accidents and external causes, and "all other causes". The group "all other causes" includes benign neoplasms and neoplasms of unspecified nature, endocrine, nutritional and metabolic diseases, disease of the blood, mental disorders, diseases of the nervous system, diseases of the digestive system, diseases of the genitourinary system, diseases of the skin, diseases of the musculoskeletal system, congenital anomalies, and the group of ill defined causes of death. For some of these cause of death groups, the total number of

Table 1 Age standardised relative indices of inequality in mortality (RII) and 95\% confidence intervals $(95 \%$ CI) over time in England and Wales versus Scotland (men 15-64 years of age)

\begin{tabular}{llll}
\hline Year & $\begin{array}{l}\text { England and Wales } \\
\text { RII }(95 \% \text { CI })\end{array}$ & $\begin{array}{l}\text { Scotland } \\
\text { RII }(95 \% \text { CI })\end{array}$ & $\begin{array}{l}\text { Significance of difference between } \\
\text { England and Wales and Scotland }\end{array}$ \\
\hline 1951 & $1.40(1.38,1.42)$ & $1.22(1.18,1.25)$ & $\mathrm{p}<0.001$ \\
1961 & $1.91(1.88,1.93)$ & $1.82(1.76,1.87)$ & $\mathrm{p}=0.005$ \\
1971 & $1.97(1.94,2.00)$ & $1.78(1.73,1.84)$ & $\mathrm{p}<0.001$ \\
1981 & $2.43(2.40,2.47)$ & $2.57(2.48,2.67)$ & $\mathrm{p}=0.006$ \\
\hline
\end{tabular}

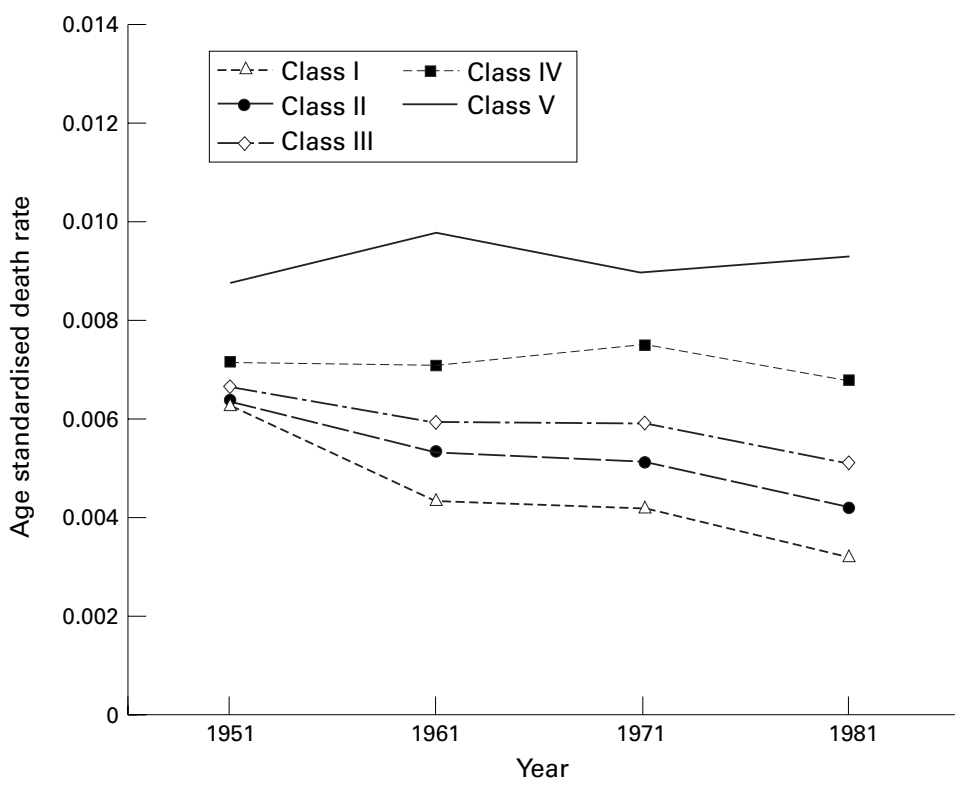

Figure 1 Age standardised death rates by social class in England and Wales. deaths per group were not reported, but only the number of deaths caused by specific causes of death (belonging to such a group) were published. This was the case for the 1951 data for both Scotland and England and Wales, and for the 1961 data from England and Wales. In these cases we added the (published) numbers for specific causes of death within a cause of death group and used that as the total number of deaths in that cause of death group, thereby implicitly assuming that the major causes of death at that time were published, so that the error resulting from this assumption would be small. However, because the number of deaths resulting from "all other causes" was calculated by subtracting the number of deaths in every cause of death group from the all cause mortality, a small proportion of the number of deaths in a particular cause of death group will have been wrongly classified into the group of "all other causes" in these years.

Poisson regression analysis was used to calculate relative indices of inequality in mortality as a measure of mortality differentials by social class, ${ }^{26}$ for each period surrounding the censuses that were carried out in Scotland and in England and Wales. A detailed description of how this measure is calculated is given in the appendix. The relative index of inequality takes into account the number of people in each social class and determines their relative position in the social hierarchy. Thus, a relative index of inequality of 2 means that the death rate of those at the bottom of the social hierarchy is twice as high as the death rate among those at the top, according to the regression equation, taking into account intermediate values between the bottom and the top. The advantage of this measure is that it takes into account the magnitude of each social class group, so that the index is less sensitive to the fact that, for instance, social class $\mathrm{V}$ has become small over time. The indices were standardised for age according to the 1981 population of Great Britain. Social class III manual and non-manual were combined because they were not separated in the early census years.

To calculate the cause specific relative index of inequality in Scotland in 1951, only the total number of deaths for men aged 15 years and older were available so that adjustment for age was not possible. This also means that deaths in those over 65 years of age were included, which will probably lead to the calculated relative index of inequality being an underestimate of the working age relative index of inequality, given the greater mortality differentials at younger ages. Age specific data were available for the calculation of the all cause relative index of inequality for Scotland in 1951, so that these were standardised for age and only considered men aged 15 to 64 years of age. For each census period we tested whether the relative index of inequality in Scotland differed from that in England and Wales, by including a country $x$ social class interaction term in the Poisson regression model. 


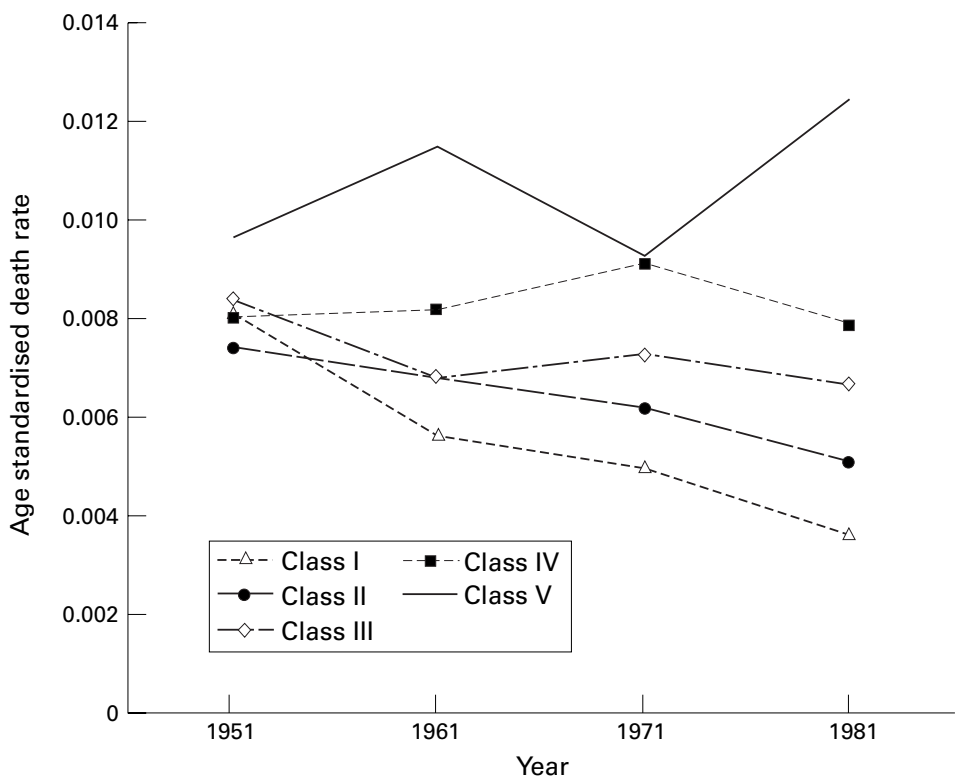

Figure 2 Age standardised death rates by social class in Scotland.

\section{Results}

Table 1 shows that the relative index of inequality for England and Wales increased considerably between 1951 and 1981. In 1951 the relative index of inequality for Scotland was smaller than that in England and Wales, but increased more between 1951 and 1981, so that by 1981 the relative index of inequality for Scotland was slightly higher than that for England and Wales. In both populations lower relative indices of inequality are found in the older age groups (data not shown).

To assess what may have caused the greater increase in the relative index of inequality over time in Scotland, age standardised death rates in each social class are presented in figures 1 and 2 (for England and Wales and Scotland respectively). It is clear that the gap in death rates between social classes has increased in both Scotland and England and Wales, although the widening of the gap has been greater in Scotland. In Scotland death rates in the more privileged social groups have decreased more over time than in England and Wales. In the other social groups, however, the death rates in Scotland decreased less over time than in England and Wales, or increased more. This combination results in a greater widening of the gap between social classes in Scotland than in England and Wales. Over the entire period, death rates were higher in Scotland in every social class.

Table 2 shows that mortality differentials by social class increase over time for several causes of death in England and Wales and Scotland. In 1951, the cause specific mortality differences were smaller in Scotland. Part of the difference between England and Wales and Scotland in this year is probably because of the fact that the Scottish cause specific relative indices of inequality were not adjusted for age and also included deaths over 65 years of age. However, the all cause relative index of inequality for Scotland was age adjusted and only considered men aged 15 to 64 , and was still lower than the index for England and Wales. By 1981 this was reversed and the all cause social class mortality differentials were more pronounced in Scotland than in England and Wales. Table 2 shows that this reversal also occurred for cardiovascular diseases, accidents and external causes, and "all other causes of death". For these cause of death groups, Scotland had smaller social class differentials in 1951, but a stronger increase over time, in particular between 1971 and 1981, resulting in greater differentials in 1981. The social class differentials in the other cause of death groups in Scotland remained smaller than or equal to those in England and Wales over time. Therefore, the reversal of the all cause social class mortality differentials, with smaller differentials in Scotland in 1951 but greater differentials in 1981, is probably because of the cause of death groups for which such a reversal is also seen (in particular if the contribution of the cause specific deaths to the total number of deaths is large).

The increasing differentials in cardiovascular disease in Scotland are mainly because of the contribution of ischaemic heart disease and cerebrovascular disease (data not shown). Part of the increasing differentials in "all other causes of death" is a result of increased differentials for diabetes mellitus and liver cirrhosis. The relative index of inequality for diabetes mellitus increased from 0.97 (95\% confidence intervals (CI) $0.81,1.15$ ) in 1951 to 2.35 $(1.99,2.78)$ in 1981 in England and Wales and from $0.38(0.29,0.51)$ to $2.17(1.43,3.31)$ in Scotland. The relative index of inequality for liver cirrhosis increased from $0.88(0.74,1.05)$

Table 2 Age standardised and cause specific relative indices of inequality in mortality (RII) and 95\% confidence intervals (95\%CI) over time in England and Wales versus Scotland (men 15-64 years of age)

\begin{tabular}{|c|c|c|c|c|c|c|c|c|c|c|c|c|}
\hline & \multicolumn{2}{|c|}{ All infectious diseases } & \multicolumn{2}{|l|}{$\begin{array}{l}\text { All malignant } \\
\text { neoplasms }\end{array}$} & \multicolumn{2}{|l|}{$\begin{array}{l}\text { All cardiovascular } \\
\text { diseases }\end{array}$} & \multicolumn{2}{|c|}{ All respiratory diseases } & \multicolumn{2}{|l|}{$\begin{array}{l}\text { All accidents and } \\
\text { external causes }\end{array}$} & \multicolumn{2}{|l|}{ All other causes } \\
\hline & RII $(95 \% C I)$ & $\%^{\star}$ & RII $(95 \% C I)$ & $\%$ & RII $(95 \% C I)$ & $\%$ & RII $(95 \% C I)$ & $\%$ & $R I I(95 \% C I)$ & $\%$ & RII $(95 \% C I)$ & $\%$ \\
\hline \multicolumn{13}{|c|}{ England and Wales } \\
\hline 1951 & $1.96(1.89,2.04)$ & 8.5 & 1.35( & 22.7 & $0.99(0$ & 33.0 & 3.26 & 11.5 & 1.44 & 8.7 & 1.38 & 16.1 \\
\hline 1961 & $3.52(3.22,3.84)$ & 1.7 & $1.85(1$ & 26.4 & $1.39(1$ & 39.4 & 4.47( & 11.0 & 2.51 & 8.9 & 2.03) & 12.6 \\
\hline 1971 & $3.88(3.28,4.58)$ & 0.8 & $1.97(1$ & 27.3 & $1.54(1.5$ & 47.4 & 4.62( & 9.6 & 2.81 & 8.1 & $1.96(1.86,2.08)$ & 6.7 \\
\hline 1981 & $3.51(2.89,4.24)$ & 0.5 & $2.30(2.25,2.36)$ & 28.5 & $2.10(2.06,2.14)$ & 48.1 & $5.79(5.47,6.12)$ & 6.6 & $3.23(3.09,3.38)$ & 9.4 & $2.57(2.44,2.71)$ & 6.9 \\
\hline \multicolumn{13}{|c|}{ Scotland } \\
\hline $1951 \dagger$ & $1.81(1.65,1.98)$ & 4.2 & & 17.3 & & 50.4 & & 9.0 & & 4.4 & & 14.6 \\
\hline 1961 & $3.12(2.54,3.84)$ & 2.3 & $1.89(1.78,2.01)$ & 24.7 & $1.38(1.31,1.44)$ & 44.6 & 4.01 & 9.7 & $2.42(2.19,2$ & 9.4 & $1.75(1.58,1.93)$ & 9.3 \\
\hline 1971 & 3.93 & 0.9 & & 25.4 & & 48.6 & & 8. & & 9.8 & & 7.1 \\
\hline 1981 & $3.23(1.98,5.28)$ & 0.6 & $2.30(2.13,2.47)$ & 25.7 & $2.29(2.17,2.42)$ & 47.3 & $5.34(4.57,6.23)$ & 6.2 & $3.34(2.99,3.74)$ & 11.7 & $2.92(2.56,3.33)$ & 8.5 \\
\hline
\end{tabular}

${ }^{\star}$ Cause specific deaths as a percentage of all deaths. †Because of the lack of age specific data in 1951, these are crude relative indices of inequality in mortality in which deaths over 65 years of age are included. 
Table 3 Standardised mortality ratios comparing Scotland with England and Wales, men aged 15-64 (England and Wales = 100)

\begin{tabular}{lll}
\hline Year & Standardised for age & Standardised for age and social class \\
\hline 1951 & 119 & 120 \\
1961 & 118 & 118 \\
1971 & 121 & 120 \\
1981 & 128 & 125
\end{tabular}

in 1961 to $1.40(1.22,1.61)$ in 1981 in England and Wales and from $0.60(0.41,0.89)$ to 1.67 $(1.26,2.22)$ in Scotland (data for 1951 are not available for Scotland). Part of the increasing social class differentials in accidents and external causes is a result of increasing differentials for suicide, which increased from 0.92 (0.86, $1.00)$ in 1951 to $1.91(1.75,2.07)$ in 1981 in England and Wales and from $0.74(0.58,0.94)$ in 1951 to $2.05(1.63,2.58)$ in 1981 in Scotland.

The contribution of cause specific mortality to the total number of deaths has changed over time, and these changes have been different in Scotland than in England and Wales for some causes of death (table 2). The contribution of accidents and external causes, for instance, has increased more over time in Scotland than in England and Wales, even from 1961 to 1981 and discounting the incomplete 1951 data for Scotland. This greater increase in Scotland was partly a result of a larger increase in the contribution of suicide (data not shown). This reflects a difference in suicide mortality over time, as the age standardised mortality resulting from suicide in men aged 15 to 64 was lower in all social classes in 1961 in Scotland than in England and Wales, but higher in Scotland by 1981 . This increase in suicide mortality in Scotland continued between 1981 and 1991. ${ }^{17}{ }^{18}$ Another example is the decreasing contribution of cardiovascular mortality in Scotland over time, compared with the increasing contribution in England and Wales. This reflected a greater decrease in age standardised cardiovascular death rates in the higher social classes in Scotland than in England and Wales, although the death rates remained higher in Scotland (data not shown).

\section{Discussion}

This study has shown that trends in inequalities in mortality differ within Great Britain. Although death rates were higher in Scotland compared with England and Wales, smaller mortality differentials by social class were found in Scotland over the period 1951 to 1971. By 1981, however, the relative index of inequality for Scotland was higher than that for England and Wales, because death rates for social class I declined more in Scotland, while the death rates of social classes IV and V remained considerably higher in Scotland than that in England and Wales over the entire period. The greater increase in social class mortality differentials in Scotland over time, in particular between 1971 and 1981, seemed to be a result of increasing differences in cardiovascular disease, accidents and external causes, and "all other causes".

\section{KEY POINTS}

- Trends in inequalities in mortality differ within Great Britain.

- Although death rates were higher in Scotland than in England and Wales from 1951 to 1971 , smaller social class mortality differentials were found in Scotland.

- The greater increase over time in the inequalities in Scotland than in England and Wales between 1971 and 1981 may have contributed to the relative worsening of the overall mortality profile of Scotland over this period.

Census data should be interpreted with caution. Mortality is classified according to social class at death, while the population at risk is classified according to social class at the time of census. This introduces a potential for the numerator-denominator bias. However, it has been shown that the influence of this bias on mortality differentials is not great. ${ }^{19}$

This study showed that Scotland had higher death rates in each social class over the entire period from 1951 to 1981 . Other studies have also shown the higher death rates in Scotland around the 1981 census. Carstairs and Morris found that the death rates in Scotland were about 25\% higher than in England and Wales around the 1981 census, standardised for age, sex, and social class. ${ }^{7}$ Standardising for deprivation measures essentially abolished the Scottish mortality disadvantage. Balarajan and McDowall similarly found that around the 1981 census Scotland had higher mortality rates compared with England and Wales, and that this difference was greater for men in the manual group than for the non-manual group. ${ }^{20}$ Table 3 shows the higher mortality in Scotland compared with England and Wales, largely independent of social class, seen over the period of interest. Furthermore, it has been shown that mortality differences between affluent and deprived groups in England and in Scotland have further increased between 1981 and $1991 . .^{172122}$

It has been suggested that (among affluent countries) the level of income inequality within a country may determine both the degree of mortality differentials within the country and the country's relative mortality compared with other countries. ${ }^{23}$ In this respect countries with higher levels of income inequality are seen to have higher death rates, independent of overall economic level. The finding has been extended to include associations between the level of socioeconomic inequality and overall mortality of areas within a country. ${ }^{24}{ }^{25}$ The mechanism, however, for this effect of income inequality is not clear. ${ }^{26}$ The income inequality hypothesis produces the expectation that countries with greater income inequality would have larger inequalities in mortality and higher overall death rates than countries with lower income inequality. Table 3, however, shows that, in contrast with this prediction, Scotland had 
higher death rates than England and Wales around the years 1951, 1961, and 1971 - that is, during a period when the mortality differentials were greater in England and Wales than in Scotland. On the other hand the increase in the mortality differential between Scotland and England and Wales between 1971 and 1981 is consistent with the income inequality hypothesis, because a greater increase in mortality differentials within Scotland than within England and Wales was associated with an increasing relative difference between them.

The authors thank Karien Stronks and Anton Kunst from the Erasmus University Rotterdam for their helpful comments and suggestions in preparing this paper. We acknowledge the help of the Office on Population Censuses and Surveys, who supplied unpublished data, and thank the Netherlands Organisation for Scientific Research (NWO) and the Spinoza fund (from the University of Amsterdam) for the travel grants (to PvdM) that enabled us to do this work.

Source of funding: none

Conflict of interest: none

\section{Appendix}

To calculate the relative index of inequality around each census year for both Scotland and for England and Wales, Poisson regression analysis was used with a socioeconomic position indicator as an independent variable. Table 4 shows how this socioeconomic position indicator is calculated (for Scotland in 1951). First the percentage of people in every social class is calculated. Then their relative position on a scale ranging from 0 to 1 is determined. To determine the relative position for people from social class III for instance, half of the proportion of people in social class III (half of 0.493) is added to the cumulative proportion in social class I and II (0.163).

This socioeconomic position indicator was then entered as an independent variable in Poisson regression analysis. The regression coefficient of the socioeconomic position indicator and the standard error were subsequently used to calculate the rate ratio with $95 \%$ confidence intervals. This rate ratio is known as the relative index of inequality. The indices were standardised for age according to the 1981 population of Great Britain. This was done by calculating age standardised death rates for

Table 4 Calculation of socioeconomic position indicator

\begin{tabular}{llll}
\hline Social class & \% Persons & Cumulative proportion & Relative position \\
\hline I Professional etc, occupations & 0.032 & 0.032 & 0.016 \\
II Intermediate occupations & 0.131 & 0.163 & 0.097 \\
III Skilled occupations & 0.493 & 0.656 & 0.409 \\
IV Partly skilled occupations & 0.194 & 0.850 & 0.752 \\
V Unskilled occupations & 0.150 & 1 & 0.925 \\
\hline
\end{tabular}

each social class during each census period, multiplying these rates (for example, for Scotland) with the (Scottish) population to obtain the number of deaths, and then entering this number of deaths into the Poisson regression analysis as the dependent variable.

1 Marmot MG, McDowall ME. Mortality decline and widening social inequalities. Lancet 1986;ii:274-6.

2 Pamuk ER. Social class inequalities in mortality from 1921 to 1972 in England and Wales. Population Studies 1985;39. $17-31$.

3 Blane D, Davey Smith G, Bartley M. Social class differences in years of potential life lost: size, trends and principal causes. BMF 1990;301:429-32.

4 Naiman JM. Health and poverty: past, present and prospects for the future. Soc Sci Med 1993;36:157-66.

5 Harding S. Social class differences in mortality of men: recent evidence from the OPCS Longitudinal Study. Popul Trends 1995;80:31-7.

6 Kunst AE, Mackenbach JP. International variation in the size of mortality differences associated with occupational status. Int F Epidemiol 1994;23:742-51.

7 Carstairs V, Morris R. Deprivation: explaining differences in mortality between Scotland and England and Wales. BMF 1989;299:886-9.

8 Davey Smith G, Shipley MJ, Hole D, et al. Explaining male mortality differentials between the west of Scotland and the south of England. [Abstract]. F Epidemiol Community Health 1995;49:541.

9 Registrar General Scotland. Hundred and first annual report of the Registrar General for Scotland 1955. Appendix IX Edinburgh: HMSO, 1957.

10 Registrar General Scotland. Occupational mortality 19591963. Second supplement to the Hundred and fourteenth annual report of the Registrar General for Scotland 1968. Edinburgh: HMSO, 1968.

11 Registrar General Scotland. Occupational mortality 19691973. Edinburgh: HMSO.

12 Office of Population Censuses and Surveys. Occupational mortality. The Registrar General's decennial supplement for Great Britain, 1979-80,1982-83. Series DS no. 6. London: HMSO, 1986 .

13 Office of Population Censuses and Surveys. The Registrar General's decennial supplement, England and Wales, 1951. Occupational mortality part II volume 2. London: HMSO, 1958.

14 Office of Population Censuses and Surveys. The Registrar General's decennial supplement, England and Wales, 1961.
Occupational mortality tables. London: HMSO, 1971.

15 Office on Population Censuses and Surveys. Occupational mortality. The Registrar General's decennial supplement for England and Wales, 1970-1972. Series DS no. 1. London: HMSO, 1978 .

16 Drever F, Whitehead M, Roden M. Current patterns and rends in male mortality by social class (based on occupation). Popul Trends 1996;86:15-20.

17 McLoone P. Suicide and deprivation in Scotland. BMf 1996;312:543-4.

18 McLoone P, Boddy FA. Deprivation and mortality in Scotland, 1981 and 1991. BMF 1994;309:1465-74.

19 Davey Smith G, Blane D, Bartley M. Explanations for socio-economic differentials in mortality. Evidence from Britain and elsewhere. Eur f Public Health 1994;4:131-44.

20 Balarajan R, McDowall ME. Regional socioeconomic Balarajan R, McDowall ME. Regional socioeconomic
differences in mortality among men in Great Britain today. Public Health 1988;102:33-43.

21 Phillimore P, Beattie A, Townsend P. Widening inequality of health in northern England, 1981-1991. BMF 1994;308: health in

22 McCarron PG, Davey Smith G, Womersley JJ. Deprivation and mortality: increasing differentials in Glasgow, 1979992. BMF 1994;309:1481-2.

23 Wilkinson RG. Unfair shares. Ilford: Banardo's, 1994.

24 Ben-Shlomo Y, White IR, Marmot M. Does the variation in the socioeconomic characteristics of an area affect mortality? $B M \mathcal{F} 1996 ; 312: 1013-14$

25 Kennedy BP, Kawachi I, Prothrow-Stith D. Income distribution and mortality: cross sectional ecological study of the Robin Hood index in the United States. BMF 1996; 312:1004-7.

26 Davey Smith G. Income inequality and mortality: why are they related? $B M F 1996 ; 312: 987-8$. 